\title{
Educação científica na perspectiva de letramento como prática social: funções, princípios e desafios
}

\author{
Wildson Luiz Pereira dos Santos
}

Universidade de Brasília, Programa de Pós-Graduação em Educação e Programa de Pós-Graduação em Ensino de Ciências

\section{Introdução}

Ao discutir sobre alfabetização científica, Chassot (2003) considera-a domínio de conhecimentos científicos e tecnológicos necessários para o cidadão desenvolver-se na vida diária. Em trabalho anterior sobre o mesmo tema, Chassot (2000) apresenta a ciência como uma produção cultural marcada principalmente por uma visão ocidental caracterizada pela nossa educação eurocêntrica. Nessa visão, pode-se considerar que sua origem cultural remonta ao século XVI. Em suas proposições, Francis Bacon (1561-1626) já apontava o papel da ciência a serviço da humanidade. A partir do século XIX, tanto na Europa como nos Estados Unidos, a ciência incorporou-se ao currículo escolar (DeBoer, 2000). Também a partir daquele século, eram encontradas na Inglaterra e nos Estados Unidos publicações de livros e artigos sobre ciências destinados ao público geral, bem como artigos que destacavam a importância do estudo da ciência pelo público (Hurd, 1998; Layton, Davey \& Jenkins, 1986; Shamos, 1995). Layton, Davey e Jenkins (1986) citam obras científicas para o público datadas do século XVIII.
No início do século XX, a alfabetização ou letramento $^{1}$ científico começou a ser debatido mais profundamente. Desses estudos iniciais, pode-se destacar o trabalho de John Dewey (1859-1952), que defendia nos Estados Unidos a importância da educação científica. Esses estudos passaram a ser mais significativos nos anos de 1950, em pleno período do movimento cientificista, em que se atribuía uma supervalorização ao domínio do conhecimento científico em relação às demais áreas do conhecimento humano. A temática tornou-se um grande slogan, surgindo um movimento mundial em defesa da educação científica.

${ }^{1}$ Na revisão de estudos sobre o significado do processo de alfabetização científica e tecnológica, tomou-se como referência artigos da literatura inglesa que empregam o termo literacy, que pode ser traduzido para o português como alfabetização ou como letramento (ou literacia, no português de Portugal). Mais adiante será apresentada uma discussão em torno de significados que podem ser atribuídos a esses dois vocábulos. Assim, neste artigo são empregadas as duas denominações, usando o termo letramento apenas quando o seu significado se referir ao uso social do conhecimento científico, na acepção adotada por Soares (1998). 
No Brasil, a preocupação com a educação científica foi mais tardia. No século XIX, o currículo escolar era marcado predominantemente pela tradição literária e clássica herdada dos jesuítas. Apesar do incentivo de dom Pedro II (1825-1891), um cultor das ciências, e de discursos positivistas de intelectuais brasileiros em favor da ciência, como Rui Barbosa (1849-1923), o ensino de ciências teve pouca prioridade no currículo escolar (Almeida Júnior, 1979). Esse ensino passou efetivamente a ser incorporado ao currículo escolar nos anos de 1930, a partir de quando começou um processo de busca de sua inovação (Krasilchik, 1980). Esse processo de inovação teve início com um processo de atualização curricular e depois continuou com a produção de kits de experimentos na década de 1950 e com a tradução de projetos americanos e a criação de centros de ensino de ciências na década de 1960, culminando com o início da produção de materiais por educadores brasileiros na década de 1970 (idem, ibidem). Foi também a partir dos anos de 1970 que teve início efetivo a pesquisa na área de educação em ciências no Brasil, a qual se foi consolidando nos últimos 35 anos, de forma que hoje se conta com uma comunidade científica atuante em mais de 30 programas de pós-graduação em ensino de ciências, com a realização regular de congressos científicos específicos nessa área e com a publicação de periódicos acadêmicos sobre a temática, tendo sido produzidas cerca de 1.100 dissertações de mestrado e teses de doutorado entre 1972 e 2003, de acordo com pesquisa de Megid Neto, Fracalanza e Fernandes (2005).

A preocupação crescente com a educação científica vem sendo defendida não só por educadores em ciências, mas por diferentes profissionais; seus objetivos têm tido uma grande abrangência. Ocorre que, tendo surgido essa temática em diferentes contextos, os autores estão longe de chegar a um consenso (Jenkins, 1990, 1997; Laugksch, 2000). Isso pode ser explicado pelo fato de a educação científica ser um conceito amplo que depende do contexto histórico no qual ela é proposta (DeBoer, 2000; Laugksch, 2000) e por depender de pressupostos ideo- lógicos e filosóficos (Aikenhead, 1997; Champagne \& Lovitts, 1989).

Nesse sentido, torna-se importante discutir os diferentes significados e funções que se têm atribuído à educação científica com o intuito de levantar referenciais para estudos na área de currículo, filosofia e política educacional que visem analisar o papel da educação científica na formação do cidadão. No presente artigo, é apresentada uma revisão de estudos desenvolvidos no âmbito da educação em ciências, visando contribuir para uma reflexão sobre as suas diferentes funções. Essa revisão fornece elementos para estudos críticos de processos avaliativos de nível de alfabetização da população brasileira e da qualidade do ensino de ciências; de análise e proposição de programas de reforma curricular; de estudos sobre políticas públicas na área de formação de professores de ciências e programas de melhoria da qualidade desse ensino, como programas de livros didáticos. Isso se torna essencial, no momento em que resultados de exames nacionais apontam como grande desafio a busca pela melhor qualidade da educação básica.

\section{Educação científica: enfoques e perspectivas de análise}

Merton (1910-2003), em seus clássicos trabalhos de sociologia da ciência, já considerava as condições sociais de produção e apropriação do conhecimento. Mesmo ao tratar a ciência do seu ponto de vista internalista, com relação às normas de seu funcionamento, Merton (1968) destacava as pressões sociais sobre a autonomia da ciência, sobretudo nos países de regimes totalitários. Com diferentes perspectivas sobre as relações entre ciência, tecnologia e sociedade, os estudiosos da sociologia da ciência foram ampliando as proposições analíticas sobre a base da organização e interação dos praticantes da ciência. Kuhn (1922-1996) destacou o papel da comunidade científica no estabelecimento dos paradigmas científicos. Bourdieu (19302002) afirmou que "a verdade científica reside numa espécie particular de condições sociais de produção; isto é, mais precisamente, num estado determinado da 
estrutura e do funcionamento do campo científico" (Bourdieu, 1994, p. 122). Ampliando a análise desse campo, outro grupo de sociólogos, como Latour e Woolgar (1979) e Knorr-Cetina (1981), identificou as condições sociais internas de produção do conhecimento científico, demonstrando como o fato científico é construído no contexto sociopolítico, no qual tomam parte vários atores, incluindo cientistas e não-cientistas, e reunindo argumentos técnicos e não-técnicos.

Fugindo do propósito de aqui fazer uma revisão das várias correntes filosóficas que tratam da perspectiva da ciência na sociedade, pode-se tomar a caracterização de Gerard Radnitzky (1970) da ciência como um sistema social essencialmente relacionado ao desenvolvimento do conhecimento. Esse sistema, ilustrado na Figura 1, é bastante útil para compreender os diferentes significados que têm sido tomados para a educação científica. No sistema apresentado, incluem-se, entre outros componentes, os produtores (cientistas), o processo de pesquisa, os produtos etc. Para Radnitzky (1970), na análise desse sistema, podese enfocar cada um de seus componentes com perspectivas diferentes. $\mathrm{O}$ enfoque nos produtos, enquanto sistemas simbólicos, pode levar a uma análise de aspectos lógicos, semânticos, teóricos e epistemológicos da ciência, enquanto o enfoque nos produtores e usuários terá uma perspectiva centrada na ciência em sociedade, com estudos de aspectos sociológicos, psicológicos, historiográficos, culturais e políticos. Certamente a análise de cada um desses componentes apresentará significados e razões diversas para o conhecimento científico.

Considerando, então, que a ciência engloba diferentes atores sociais e que a compreensão desse campo depende da análise das inter-relações entre esses atores, pode-se considerar que a compreensão dos propósitos da educação científica passa por uma análise dos diferentes fins que vêm sendo atribuídos a ela pelos seus diversos atores.

$\mathrm{Na}$ área de pesquisa de ensino de ciências (Gilbert, 1995), estudos sobre educação científica vêm sendo desenvolvidos com a denominação scientific literacy, estando também associados a estudos sobre
Figura 1 - O sistema ciência-sociedade

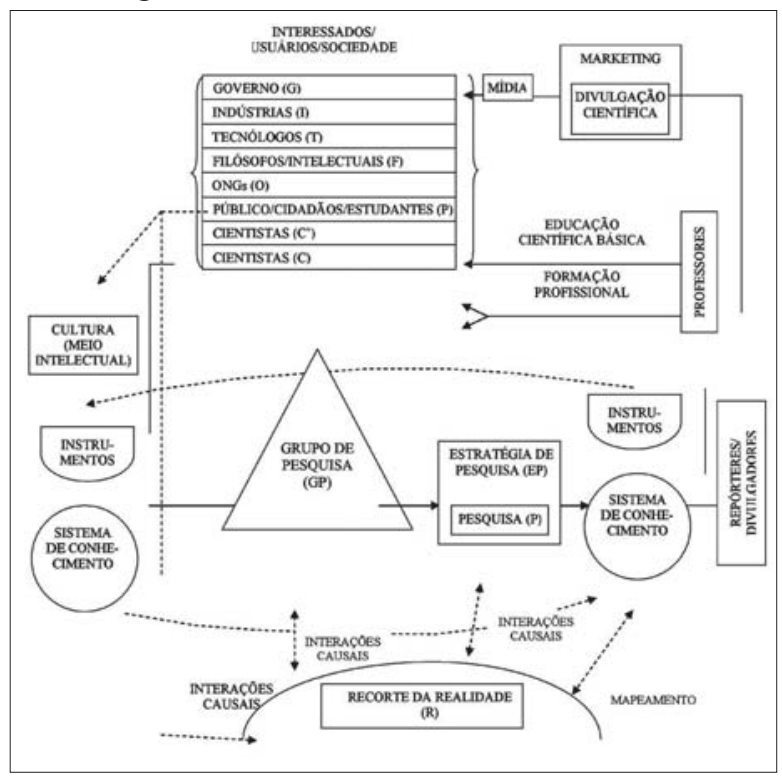

Adaptado de Radnitzky (1970).

scientific and technological literacy (STL). Essa terminologia pode ser traduzida como alfabetização científica (AC ou ACT, quando se inclui a tecnologia) ou como letramento científico (LC ou LCT).

Em artigo de revisão sobre $\mathrm{AC} / \mathrm{LC}$, Laugksch (2000) identificou vários fatores que influenciam interpretações do significado da educação científica. Para ele, tais fatores incluem a existência de diferentes grupos de atores sociais preocupados com a educação científica, diferentes definições conceituais para os termos alfabetização ou letramento, diferentes propósitos para essa educação, assim como diferentes estratégias que têm sido adotadas na mensuração do nível de alfabetização das pessoas sobre ciência.

Para Laugksch (2000), o entendimento do significado de AC/LC tem sido objeto de preocupação de educadores em ciência, cientistas sociais, pesquisadores de opinião pública, sociólogos da ciência, e profissionais envolvidos na educação formal e nãoformal em ciências, como professores e profissionais que trabalham com a divulgação da ciência, jornalistas e profissionais de museus, centros de ciências, parques ambientais, jardins botânicos etc. (Figura 2).

Cada um desses grupos sociais terá enfoque diferente para os diversos contextos de AC/LC. Enquan- 
Figura 2 - Alguns atores sociais interessados em letramento científico e tecnológico

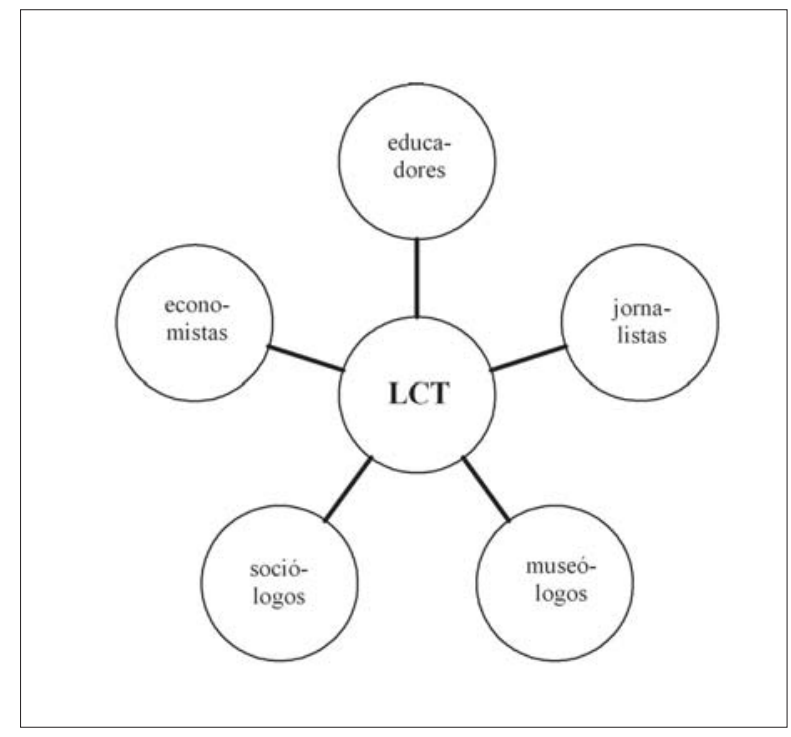

to os educadores em ciência se preocupam com a educação nos sistemas de ensino, os cientistas sociais estão voltados para o interesse do público em geral por questões científicas; os sociólogos, envolvidos com a interpretação diária da ciência; os comunicadores da ciência, com a divulgação científica em sistemas não-formais; e os economistas, interessados no crescimento econômico decorrente do maior consumo da população por bens tecnológicos mais sofisticados que requerem conhecimentos especializados, como o uso da informática.

Com essas perspectivas diferentes, surgem também diversos argumentos para justificar AC/LC. Millar (1996) agrupa esses argumentos em cinco categorias: a) argumento econômico, que conecta o nível de conhecimento público da ciência com o desenvolvimento econômico do país; b) utilitário, que justifica o letramento por razões práticas e úteis; c) democrático, que ajuda os cidadãos a participar das discussões, do debate e da tomada de decisão sobre questões científicas; d) social, que vincula a ciência à cultura, fazendo com que as pessoas fiquem mais simpáticas à ciência e à tecnologia; e e) cultural, que tem como meta fornecer aos alunos o conhecimento científico como produto cultural.
Todos esses argumentos, de alguma forma, estão presentes no currículo escolar e constituem fatores de influência no seu planejamento. Assim, se a prioridade da alfabetização for melhorar o campo de conhecimento científico, preparando novos cientistas, o enfoque curricular será centrado em conceitos científicos; se o objetivo for voltado para a formação da cidadania, o enfoque englobará a função social e o desenvolvimento de atitudes e valores (Ratcliffe \& Grace, 2003).

\section{Domínios da educação científica: alfabetização e letramento}

A ênfase curricular no ensino de ciências proposta pelos educadores em ciência tem mudado em função de contextos sócio-históricos. No final dos anos de 1950, em plena Guerra Fria, com o lançamento do primeiro satélite artificial - o Sputinik -, houve, da parte dos Estados Unidos, uma corrida para apressar a formação de cientistas, o que levou à elaboração de projetos curriculares com ênfase na vivência do método científico, visando desenvolver nos jovens o espírito científico (Krasilchik, 1987). Naquela época, propunha-se uma educação científica para a educação básica, no sentido de preparar os jovens para adquirir uma postura de cientista, pensando e agindo no seu cotidiano como cientistas.

No final da década seguinte, com o agravamento de problemas ambientais, começou a surgir uma preocupação dos educadores em ciência por uma educação científica que levasse em conta os aspectos sociais relacionados ao modelo de desenvolvimento científico e tecnológico. Foi assim que começou a surgir em diversos países, no final dos anos de 1970 e no início da década seguinte, propostas curriculares para a educação básica com ênfase nas inter-relações ciência-tecnologia-sociedade (CTS) (Waks, 1990; Yager \& Roy, 1993). Esses currículos apresentavam o conteúdo de ciências da natureza com enfoque nas ciências sociais. Tais propostas tinham uma perspectiva marcadamente ambientalista, apresentando uma visão crítica ao modelo de desenvolvimento; por 
isso, alguns a identificaram como ciência-tecnologiasociedade-ambiente (CTSA).

Outros enfoques para a educação científica continuaram a surgir. Enquanto alguns autores defendiam a educação para a ação social responsável, a partir de uma análise crítica sobre as implicações sociais da ciência e da tecnologia, outros passaram a defender a compreensão da natureza da atividade científica como aspecto central na educação científica. Assim, diferentes concepções e perspectivas foram sendo propostas sobre o que seria AC/LC. Em uma revisão sobre essas concepções, Norris e Phillips (2003) identificaram os seguintes significados para essa educação: a) conhecimento do conteúdo científico e habilidade em distinguir ciência de não-ciência; b) compreensão da ciência e de suas aplicações; c) conhecimento do que vem a ser ciência; d) independência no aprendizado de ciência; e) habilidade para pensar cientificamente; e) habilidade de usar conhecimento científico na solução de problemas; f) conhecimento necessário para participação inteligente em questões sociais relativas à ciência; g) compreensão da natureza da ciência, incluindo as suas relações com a cultura; h) apreciação do conforto da ciência, incluindo apreciação e curiosidade por ela; i) conhecimento dos riscos e benefícios da ciência; ou j) habilidade para pensar criticamente sobre ciência e negociar com especialistas.

O que sobressai da leitura dos trabalhos de AC/ LC, muitos dos quais estão na revisão de Norris e Phillips (2003) sumarizada nos domínios anteriores, é o fato de cada autor enfatizar determinados domínios, apresentando argumentos filosóficos diferentes para sustentar seu posicionamento. Esses autores, embora não coincidam com enunciados que caracterizam $\mathrm{AC}$ ou $\mathrm{LC}$, em tese incluem sempre dois grandes grupos de categorias: um que incorpora as relativas à especificidade do conhecimento científico, e outro que abrange as categorias relativas à função social.

Nesse sentido, pode-se observar que os domínios das categorias de a) a e) anteriores se referem ao conhecimento e ao desenvolvimento de habilidades em relação à atividade científica. Já as categorias de f) a k) referem-se a conhecimentos, habilidades e valores relacionados à função social da atividade científica, incluindo categorias de natureza cultural, prática e democrática.

Esses dois grandes domínios estão centrados no compreender o conteúdo científico e no compreender a função social da ciência. Apesar de serem enfatizados de formas diferentes pelos autores que discutem educação científica, eles estão inter-relacionados e imbricados. Pela natureza do conhecimento científico, não se pode pensar no ensino de seus conteúdos de forma neutra, sem que se contextualize o seu caráter social, nem há como discutir a função social do conhecimento científico sem uma compreensão do seu conteúdo. Afinal, como afirma Morin (2000), há um tecido interdependente e inter-retroativo entre o objeto do conhecimento e o seu contexto.

Isso, contudo, não tem sido a característica da educação científica na educação formal, que desde o ensino fundamental até a pós-graduação vem sendo abordada cada vez mais com fragmentação e especialização. Dessa forma, as discussões sobre educação científica muitas vezes acabam por priorizar um domínio em relação a outro.

Sem querer propor uma dicotomia entre os dois domínios, no presente artigo, caracteriza-se essa distinção adotando a mesma categorização que se vem usando para alfabetização e letramento nas ciências lingüísticas e em educação. Para Magda Soares (1998), o termo alfabetização tem sido empregado com o sentido mais restritivo de ação de ensinar a ler e a escrever; o termo letramento refere-se ao "estado ou condição de quem não apenas sabe ler e escrever, mas cultiva e exerce práticas sociais que usam a escrita" (p. 47).

De acordo com essa conceituação, uma pessoa alfabetizada, que sabe ler e escrever, pode não ser letrada, caso não faça uso da prática social de leitura, ou seja, apesar de ler, não é capaz de compreender o significado de notícias de jornais, avisos, correspondências, ou não é capaz de escrever cartas e recados. Isso é o que se tem chamado de analfabetismo fun- 
cional. Ao contrário, uma pessoa pode não ser alfabetizada, mas ser letrada se tiver contato diário com as informações do mundo da leitura e da escrita, por meio de pessoas que lêem ou escrevem para ela as notícias de jornal, as cartas ou os recados (Soares, 1998).

Chassot (2000) considera inadequado o termo alfabetização, pois carrega a primazia da óptica ocidental da escrita alfabética, desconsiderando a linguagem de outras civilizações que adotaram escritas cuneifórmica, hieroglífica e ideogrâmica. Todavia, Chassot (2000), em sua obra, acaba adotando o termo alfabetização, mencionando que letramento não está dicionarizado e que letrado apresenta conotações pernósticas. Krasilchik e Marandino (2004) entendem que o termo alfabetização científica já se consolidou na prática social, apesar da distinção entre alfabetização e letramento. Nesse sentido, elas consideram que a alfabetização já engloba a idéia de letramento.

Neste artigo, adota-se a diferenciação entre alfabetização e letramento, pois na tradição escolar a alfabetização científica tem sido considerada na acepção do domínio da linguagem científica, enquanto o letramento científico, no sentido do uso da prática social, parece ser um mito distante da prática de sala de aula. Ao empregar o termo letramento, busca-se enfatizar a função social da educação científica contrapondo-se ao restrito significado de alfabetização escolar.

Nesse sentido, a conceituação apresentada por Krasilchik e Marandino (2004) para alfabetização como "capacidade de ler, compreender e expressar opiniões sobre ciência e tecnologia" (p. 26) corresponderia ao que se denomina aqui letramento científico. Note-se que essa caracterização é também muito próxima do que Chassot (2000) considerou alfabetização: "conjunto de conhecimentos que facilitariam aos homens e mulheres fazer uma leitura do mundo onde vivem" (p. 34).

Deve-se observar que, enquanto a alfabetização pode ser considerada o processo mais simples do domínio da linguagem científica e enquanto o letramento, além desse domínio, exige o da prática social, a educação científica almejada em seu mais amplo grau envolve processos cognitivos e domínios de alto ní- vel. Shamos (1995) denominou letramento ${ }^{2}$ científico propriamente dito o processo que envolve um conhecimento mais aprofundado dos construtos teóricos da ciência e da sua epistemologia, com compreensão dos elementos da investigação científica, do papel da experimentação e do processo de elaboração dos modelos científicos. Letramento científico, nessa perspectiva, consiste na formação técnica do domínio das linguagens e ferramentas mentais usadas em ciência para o desenvolvimento científico. Para isso, os estudantes deveriam ter amplo conhecimento das teorias científicas e ser capazes de propor modelos em ciência. Isso exige não só o domínio vocabular mas a compreensão de seu significado conceitual e o desenvolvimento de processos cognitivos de alto nível de elaboração mental de modelos explicativos para processos e fenômenos. Esse domínio do letramento científico foi identificado por Shamos (1995) como "true" scientific literacy (letramento científico autêntico ou propriamente dito); por Laugksch (2000), como erudição ou competência.

\section{Letramento científico e a função social}

O conceito de letramento no sentido da prática social está muito presente na literatura de educação científica. Shamos (1995) considera que um cidadão letrado não apenas sabe ler o vocabulário científico, mas é capaz de conversar, discutir, ler e escrever coerentemente em um contexto não-técnico, mas de forma significativa. Isso envolve a compreensão do impacto da ciência e da tecnologia sobre a sociedade em uma dimensão voltada para a compreensão pública da ciência dentro do propósito da educação básica de formação para a cidadania (Santos \& Schnetzler, 1997).

${ }^{2}$ Consideramos esse domínio como letramento, pois, sendo o maior domínio na educação científica, ele confere capacidade cognitiva ao estudante de fazer uso social do conhecimento científico. 
Laugksch (2000) define LC com função social como aquele que desenvolve a capacidade mínima funcional para agir como consumidor e cidadão. Isso corresponderia à categoria cívica de Shen (1975), a qual se refere ao conhecimento essencial que as pessoas necessitam para compreender as políticas públicas, visando prepará-las para atuar na sociedade, quer compreendendo os processos relativos ao seu cotidiano e os problemas sociais vinculados à ciência e tecnologia, quer participando do processo de decisão sobre questões envolvendo saúde, energia, alimentação, recursos naturais, ambiente e comunicação. Prewitt (1983) considera que o letramento científico para cidadão tem origem nas interações entre a ciência e a sociedade e promove o que ele chama de savvy citizen ("cidadão prático"): aquele que, apesar de não ser cientista ou tecnólogo, é capaz de atuar na sociedade em nível pessoal e social, compreendendo com perspicácia a profundidade, os princípios e as estruturas que governam situações complexas, compreendendo como a ciência e a tecnologia influenciam a sua vida. Para Fourez (1997, p. 51),

[...] as pessoas poderiam ser consideradas cientifica e tecnologicamente letradas quando seus conhecimentos e habilidades dão a elas um certo grau de autonomia (a habilidade de ajustar suas decisões às restrições naturais ou sociais), uma certa habilidade de se comunicar (selecionar um modo de expressão apropriado) e um certo grau de controle e responsabilidade em negociar com problemas específicos (técnico, mas também emocional, social, ético e cultural). (tradução livre)

Nesse contexto, o letramento dos cidadãos vai desde o letramento no sentido do entendimento de princípios básicos de fenômenos do cotidiano até a capacidade de tomada de decisão em questões relativas a ciência e tecnologia em que estejam diretamente envolvidos, sejam decisões pessoais ou de interesse público. Assim, uma pessoa funcionalmente letrada em ciência e tecnologia saberia, por exemplo, preparar adequadamente diluições de produtos domissanitários; compreender satisfatoriamente as especificações de uma bula de um medicamento; adotar profilaxia para evitar doenças básicas que afetam a saúde pública; exigir que as mercadorias atendam às exigências legais de comercialização, como especificação de sua data de validade, cuidados técnicos de manuseio, indicação dos componentes ativos; operar produtos eletroeletrônicos etc. Além disso, essa pessoa saberia posicionar-se, por exemplo, em uma assembléia comunitária para encaminhar providências junto aos órgãos públicos sobre problemas que afetam a sua comunidade em termos de ciência e tecnologia.

O letramento como prática social implica a participação ativa do indivíduo na sociedade, em uma perspectiva de igualdade social, em que grupos minoritários, geralmente discriminados por raça, sexo e condição social, também pudessem atuar diretamente pelo uso do conhecimento científico (Roth \& Lee, 2004). Isso requer também o desenvolvimento de valores (Santos \& Schnetzler, 1997), vinculados aos interesses coletivos, como solidariedade, fraternidade, consciência do compromisso social, reciprocidade, respeito ao próximo e generosidade. Eles estão relacionados às necessidades humanas e deveriam ser vistos como não subordinados aos valores econômicos.

Por exemplo: as pessoas lidam diariamente com dezenas de produtos químicos e têm que decidir qual devem consumir e como fazê-lo. Essa decisão poderia ser tomada levando em conta não só a eficiência dos produtos para os fins que se desejam mas também seus efeitos sobre a saúde, seus efeitos ambientais, seu valor econômico, as questões éticas relacionadas à sua produção e comercialização. Por exemplo, poderia ser considerado pelo cidadão, na hora de consumir determinado produto, se na sua produção é usada mão-de-obra infantil ou se os trabalhadores são explorados de maneira desumana; se em alguma fase, da produção ao descarte, houve geração de resíduos que agridem o ambiente; se ele é objeto de contrabando ou de outra contravenção etc.

Outro significado que tem sido atribuído à alfabetização/letramento científico é o cultural. Esse papel dado à educação científica está presente em muitos dos estudos sobre $\mathrm{AC} / \mathrm{LC}$, de tal modo que hoje a 
educação científica tem sido vista como processo de enculturação. Um recente trabalho do escritório da Organização das Nações Unidas para a Educação, a Ciência e a Cultura (UNESCO) no Brasil sobre educação científica intitulou-a cultura científica (Macedo, 2003). Krasilchik e Marandino (2004) caracterizam a educação científica também como a capacidade de participar da cultura científica da maneira que cada cidadão, individual e coletivamente, considera oportuno. Em sua tese de doutorado, Leodoro (2005) ressalta o aspecto valorativo da educação científica no sentido de ela ser assumida pelos educandos como cultura científica, não apenas no sentido da vulgarização de seu conhecimento mas também do exercício crítico de seu modo de pensar.

O entendimento do significado cultural da educação científica vem manifestando-se com diferentes conceituações. A partir do trabalho original de 1959 de Snow (1995), em que identificou a existência de duas culturas, a científica e a humanística, Shen (1975) identificou um tipo de letramento como LC cultural. Para ele, essa categoria de letramento significava o conhecimento que os indivíduos adquirem para transpor as diferenças entre as culturas científica e humanística. DeBoer (2000) apresenta, entre outros propósitos para o letramento, o ensino e a aprendizagem de ciências como uma força cultural no mundo moderno e a aprendizagem de ciências por seus apelos estéticos. Para Ramsey (1993), o letramento cultural lida com a compreensão da ciência como principal realização humana e como parte de nossa cultura geral. Fleming (1989) considera que uma pessoa letrada é aquela que tem acesso à cultura e pode ser capaz de mover-se além dela para criar novas formas de cultura. Arons (1983) define LC como um processo que, além de considerar a ciência um corpo de conhecimento e habilidades, considera-a um produto da mente humana, de natureza experimental, que tem limites e que interage com a sociedade nos seus planos moral e ético. Já Driver e colegas $(1994)^{3}$ consideram a edu-

\footnotetext{
${ }^{3}$ Uma tradução desse artigo foi publicada na revista Química Nova na Escola, n. 9, p. 31-40, maio 1999.
}

cação científica um processo de enculturação em que o aluno aprende a linguagem, o modo de pensar, de expressar-se e de justificar os seus argumentos.

Com essas perspectivas, deve-se considerar que o processo de letramento não deve ser tomado apenas com um caráter prático, no sentido de ter uma aplicação imediata, o que Shen (1975) denominou LC prático, ${ }^{4}$ afinal, o conhecimento científico faz parte da cultura humana e possui valor por si mesmo. Nesse sentido, pode-se considerar que muitos conteúdos científicos se justificam não pelo seu caráter prático imediato, mas pelo seu valor cultural. Contudo, não se quer com isso justificar conteúdos que aparecem como penduricalhos nos programas escolares, como classificações descontextualizadas sem qualquer significado no campo científico e vocábulos obsoletos. Há de considerar-se, ainda, que conteúdos científicos com valor cultural, quando contextualizados, passam a ter significado para os alunos. Ocorre que a forma descontextualizada como o ensino de ciências é praticado nas escolas faz com que muitos dos conceitos científicos se transformem em palavreados tomados como meros ornamentos culturais repetidos pelos alunos sem qualquer significação cultural.

\section{Ensino de ciência-tecnologia-sociedade e letramento científico}

Segundo Aikenhead (1997), o movimento CTS surgiu em um contexto diferente do movimento de LCT. Enquanto o primeiro movimento surgiu pelo contexto marcado pela crítica ao modelo de desenvolvimento científico e tecnológico, o segundo nasceu por pressões sociais pelas mais diferentes razões, desde as econômicas até as práticas. Apesar da diferença de contexto, tanto os estudiosos de CTS quanto

${ }^{4}$ Para Shen (1975), o letramento prático significa a "posse do tipo de conhecimento científico e técnico que pode ser imediatamente usado para ajudar a melhorar o padrão de vida das pessoas" (p. 265), o que se relaciona com as necessidades humanas básicas de alimentação, saúde e habitação. 
os de LCT apresentam pontos em comum, quando destacam a função social do ensino de ciências.

Cursos de CTS para o ensino de ciências têm sido propostos tanto para a educação básica quanto para cursos superiores e até de pós-graduação. O objetivo central desse ensino na educação básica é promover a educação científica e tecnológica dos cidadãos, auxiliando o aluno a construir conhecimentos, habilidades e valores necessários para tomar decisões responsáveis sobre questões de ciência e tecnologia na sociedade e atuar na solução de tais questões (Aikenhead, 1994; Santos \& Mortimer, 2000; Santos \& Schnetzler, 1997; Solomon, 1993; Teixeira, 2003; Yager, 1990).

Segundo Roberts (1991), currículos de ciências com ênfase em CTS são aqueles que tratam das interrelações entre explicação científica, planejamento tecnológico e solução de problemas e tomada de decisão sobre temas práticos de importância social. Assim, uma proposta curricular de CTS pode ser vista como uma integração entre educação científica, tecnológica e social (Figura 3), em que os conteúdos científicos e tecnológicos são estudados juntamente com a discussão de seus aspectos históricos, éticos, políticos e socioeconômicos (López e Cerezo, 1996).

Figura 3 - Orientações curriculares do ensino de CTS (Aikenhead, 1990)

No Brasil, desde a década de 1970, já havia edu-

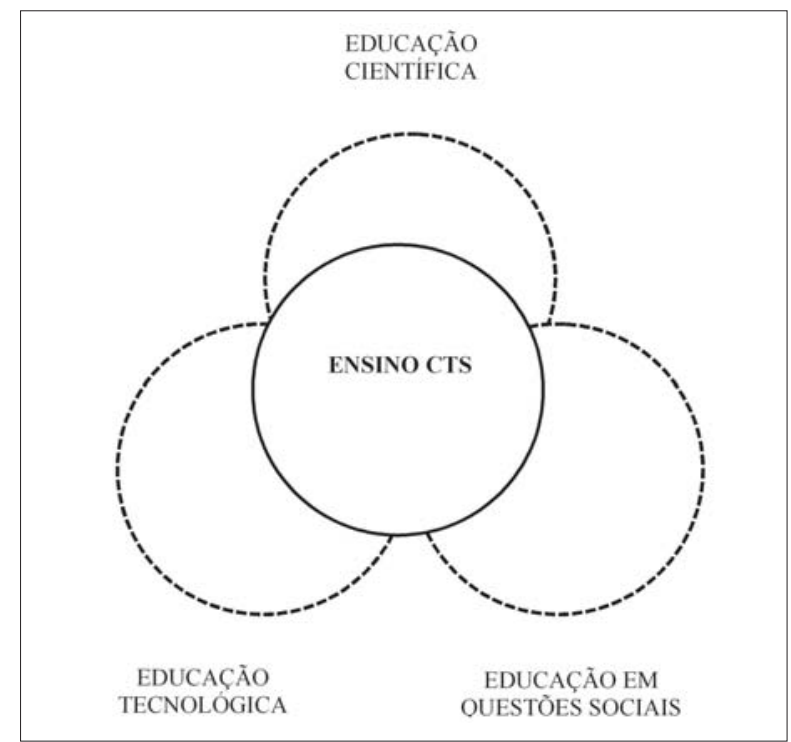

cadores preocupados em inserir no currículo escolar de ciências questões relativas aos efeitos ambientais decorrentes do desenvolvimento tecnológico (Krasilchik, 1987). Todavia, apesar da existência de propostas curriculares em outros países com a denominação CTS desde a década de 1980, aqui essa denominação só começou a surgir a partir da década de 1990 (Leal \& Gouvêa, 2002), sendo que o seu uso ainda não se popularizou. No capítulo da área de conhecimento das ciências naturais, matemática e suas tecnologias dos documentos Parâmetros Curriculares Nacionais do Ensino Médio (Brasil, 1999) e PCN + Ensino Médio (Brasil, 2002), há uma nítida proposição curricular com enfoque CTS, que surge com a denominação de contextualização, com várias recomendações e proposições de competências que inserem a ciência e suas tecnologias em um processo histórico, social e cultural e a discussão de aspectos práticos e éticos da ciência no mundo contemporâneo.

Os currículos CTS apresentam uma contribuição significativa para o LC, uma vez que incluem aspectos da educação tecnológica no ensino de ciências, conforme demonstra Bazzo (1998) ao discutir a educação tecnológica e o ensino CTS. De certa forma, a educação tecnológica não tem sido adequadamente contemplada nas disciplinas científicas da educação básica no Brasil. Em geral, os professores de ciências parecem entender que essa educação se restringe ao conhecimento de princípios de funcionamento de determinados aparatos tecnológicos. O pouco que se tem feito em sala de aula é apresentar aos alunos como o conhecimento científico está presente em diferentes recursos tecnológicos de seu cotidiano. Isso está muito longe do que se tem discutido sobre educação tecnológica em uma proposta de ensino de ciências com ênfase em CTS.

Considerando a tecnologia como uma prática que envolve aspectos técnicos, organizacionais e culturais (Pacey, 1990), pode-se destacar que o letramento tecnológico implica a compreensão de como a tecnologia é dependente dos sistemas sociopolíticos e dos valores e ideologias da cultura em que está inserida. Segundo Fleming (1989), "uma pessoa letrada tecno- 
logicamente tem o poder e a liberdade de usar esse poder para examinar e questionar os problemas de importância em sociotecnologia" (p. 393, tradução livre). Nesse mesmo sentido, Vargas (1994) afirma: "uma nação adquire autonomia tecnológica não necessariamente quando domina um ramo de alta tecnologia, mas quando consegue uma ampla e harmoniosa interação entre esses subsistemas tecnológicos, sob o controle, orientação e decisão dos 'filtros sociais"” (p. 186).

Grinspun (1999), ao discutir o que se pode entender por educação tecnológica, destaca que ela não pode ser compreendida como apenas se referindo ao ensino técnico-profissional. Para ela, a educação tecnológica deve ser também vivenciada em todos os segmentos de ensino, visando à formação de cidadãos críticos que possam transformar o modelo de desenvolvimento tecnológico de nossa sociedade atual.

Nesse sentido, cabe analisar as visões de tecnologia que Auler e Delizoicov (2001) consideram presentes em processos de LCT: a reducionista e a ampliada.

A reducionista, em nossa análise, desconsidera a existência de construções subjacentes à produção do conhecimento científico-tecnológico, tal como aquela que leva a uma concepção de neutralidade da Ciência-Tecnologia. Relacionamos a esta compreensão de neutralidade os denominados mitos: superioridade do modelo de decisões tecnocráticas, perspectiva salvacionista da Ciência-Tecnologia e o determinismo tecnológico. A perspectiva ampliada [...] busca a compreensão das interações entre CiênciaTecnologia-Sociedade (CTS), associando o ensino de conceitos à problematização desses mitos. (Auler \& Delizoicov, 2001, p. 105)

Pensar, então, em uma educação científica crítica significa fazer uma abordagem com a perspectiva de LCT com a função social de questionar os modelos e valores de desenvolvimento científico e tecnológico em nossa sociedade. Isso significa não aceitar a tecnologia como conhecimento superior, cujas decisões são restritas aos tecnocratas. Ao contrário, o que se espera é que o cidadão letrado possa participar das decisões democráticas sobre ciência e tecnologia, que questione a ideologia dominante do desenvolvimento tecnológico. Não se trata de simplesmente preparar o cidadão para saber lidar com essa ou aquela ferramenta tecnológica ou desenvolver no aluno representações que o preparem a absorver novas tecnologias.

\section{Currículos de ciências e letramento científico}

A educação científica na perspectiva do letramento como prática social implica um desenho curricular que incorpore práticas que superem o atual modelo de ensino de ciências predominante nas escolas. Entre as várias mudanças metodológicas que se fazem necessárias, três aspectos vêm sendo amplamente considerados nos estudos sobre as funções da alfabetização/letramento científico: natureza da ciência, linguagem científica e aspectos sociocientíficos.

\section{Natureza da ciência}

Aprender ciência significa compreender como os cientistas trabalham e quais as limitações de seus conhecimentos. Isso implica conhecimentos sobre história, filosofia e sociologia da ciência (HFSC).

A introdução de conteúdo de HFSC no ensino de ciências está presente em pesquisas em ensino de ciências já há algum tempo, como discutem Matthews (1992, ${ }^{5}$ 1994) e Gil-Pérez (1993). Todos esses estudos apontam para a necessidade da compreensão da natureza da ciência nesse ensino (Barra, 1998; Nascimento, 2004; Peduzzi, 2001; Ryder, 2001), o que é essencial para a compreensão das implicações sociais da ciência, uma vez que o aluno passa a entender a ciência como atividade humana e não simplesmente como atividade neutra distante dos problemas sociais (Stiefel, 1995). Solomon (1988) discute que, ao apre-

${ }^{5}$ Uma tradução desse artigo foi publicada no Caderno Catarinense de Ensino de Física, v. 12, n. 3, p. 164-214, dez. 1995. 
sentar-se o caráter provisório e incerto das teorias científicas, os alunos podem avaliar as aplicações da ciência, levando em conta as opiniões controvertidas dos especialistas. Ao contrário, com uma visão de ciência como algo absolutamente verdadeiro e acabado, os alunos terão dificuldade de aceitar a possibilidade de duas ou mais alternativas para resolver um determinado problema.

Cachapuz e colegas (2005) apresentam resultados de pesquisas sobre visões de ciência no ensino de ciências que evidenciam o que eles denominam visão deformada de ciências. Segundo eles, o ensino de ciências tem veiculado uma imagem reducionista e distorcida da ciência, visão que a apresenta como sendo descontextualizada, individualista e elitista, empíricaindutivista e ateórica, rígida, algorítmica e infalível, aproblemática e anistórica e acumulativa. Isso está relacionado à forma como esse ensino vem sendo abordado na escola em um modelo por transmissão em que não há reflexão epistemológica. Nesse sentido, para que ocorra o letramento científico torna-se fundamental uma mudança de abordagem no ensino de ciências, de forma que os estudantes desenvolvam estudos de HFSC, compreendendo a natureza da atividade científica.

\section{Linguagem científica}

Um clássico estudo dos lingüistas Halliday e Martin (1993) demonstra que a linguagem científica apresenta características próprias que a distingue da linguagem cotidiana. Mortimer (1998), explorando esses trabalhos e de Bakhtin (1992, 1997), demonstra que a linguagem científica é um gênero de discurso que foi construído socialmente pelos cientistas em sua prática. Para Mortimer (1998), enquanto a linguagem científica é estrutural e aparentemente descontextualizada, sem narrador, nominalizando processos, a linguagem cotidiana é linear, automática, dinâmica, geralmente produzida por um narrador em uma seqüência de eventos. Destaca ainda esse autor que a peculiaridade do gênero de discurso científico o torna estranho e pouco acessível aos alunos. Halliday e
Martin (1993) apontam ainda que, além da estrutura semântica, o discurso científico busca organizar os fenômenos por meio de classificações e de apresentação de relatórios, que constituem um gênero de discurso marcado pelo uso de diagramas, esquemas, gráficos e ilustrações.

Ensinar ciência significa, portanto, ensinar a ler sua linguagem, compreendendo sua estrutura sintática e discursiva, o significado de seu vocabulário, interpretando suas fórmulas, esquemas, gráficos, diagramas, tabelas etc. Além disso, Newton, Driver e Osborne (1999) consideram que o ensino de ciências deve ajudar o aluno a construir um argumento científico, o qual é diferente da argumentação do senso comum. Como demonstram Osborne, Erduran e Monk (2001), a linguagem escolar geralmente é fundamentada mais em argumentos de autoridade do que em justificativas assentadas em valores científicos, e, dessa forma, o ensino de ciências deveria dar maior atenção ao desenvolvimento da argumentação científica.

Ainda nesse sentido, Brown, Reveles e Kelly (2005) afirmam que alfabetização/letramento científíco corresponde ao uso de termos técnicos, a aplicação de conceitos científicos, a avaliação de argumentos baseados em evidências e o estabelecimento de conclusões a partir de argumentos apropriados.

Ocorre que a escola tradicionalmente não vem ensinando os alunos a fazer a leitura da linguagem científica e muito menos a fazer uso da argumentação científica. $\mathrm{O}$ ensino de ciências tem-se limitado a um processo de memorização de vocábulos, de sistemas classificatórios e de fórmulas por meio de estratégias didáticas em que os estudantes aprendem os termos científicos, mas não são capazes de extrair o significado de sua linguagem.

Norris e Phillips (2003) enfatizam a necessidade de mudança de sentido dessa alfabetização. Eles comentam que muitas discussões em torno do papel da alfabetização/letramento científico têm enfatizado as questões sociais e dado pouca prioridade ao ensino da linguagem científica. Segundo eles, mesmo o ensino tradicional de ciências não está preparando os 
estudantes para compreender o significado do conhecimento científico. Um cidadão, para fazer uso social da ciência, precisa saber ler e interpretar as informações científicas difundidas na mídia escrita. Aprender a ler os escritos científicos significa saber usar estratégias para extrair suas informações; saber fazer inferências, compreendendo que um texto científico pode expressar diferentes idéias; compreender o papel do argumento científico na construção das teorias; reconhecer as possibilidades daquele texto, se interpretado e reinterpretado; e compreender as limitações teóricas impostas, entendendo que sua interpretação implica a não-aceitação de determinados argumentos (Norris \& Phillips, 2003).

Ainda nesse sentido, Wellington e Osborne (2001) apresentam sugestões de estratégias de trabalhar a linguagem científica a partir de textos científicos de jornais, assim como Norris e Phillips (2003) discutem as implicações da leitura desses textos para o ensino. Em outro trabalho, Ogborn (2003) apresentou como no curso de física "Advancing Physics" se exploram imagens modernas da ciência, como fotos de satélites e imagens de microscópio de tunelamento eletrônico, e como se ensina os alunos a interpretar gráficos, esquemas e diagramas, relacionando-os à observação de fenômenos. O que se conclui de todos esses estudos é que, mais do que ensinar a ler vocábulos, os professores deveriam estar preocupados em ensinar os alunos a ler e compreender textos científicos.

\section{Aspectos sociocientíficos}

Outra orientação que tem sido proposta para o LC é a inclusão de aspectos sociocientíficos (ASC) no currículo; esses aspectos referem-se às questões ambientais, políticas, econômicas, éticas, sociais e culturais relativas à ciência e tecnologia (Santos, 2002). Eles têm sido amplamente recomendados no ensino de ciências com diferentes objetivos (Kolstø, 2001; Ramsey, 1993; Ratcliffe, 1998; Ratcliffe \& Grace, 2003; Rubba, 1991; Zeidler et al., 2005), os quais podem ser agrupados nas seguintes categorias:
1) relevância - encorajar os alunos a relacionar suas experiências escolares em ciências com problemas de seu cotidiano e desenvolver responsabilidade social; 2) motivação - despertar maior interesse dos alunos pelo estudo de ciências; 3) comunicação e argumentação - ajudar os alunos a verbalizar, ouvir e argumentar; 4) análise - ajudar os alunos a desenvolver raciocínio com maior exigência cognitiva; 5) compreensão - auxiliar na aprendizagem de conceitos científicos e de aspectos relativos à natureza da ciência (Ratcliffe, 1998).

A introdução de ASC, inicialmente proposta em currículos de CTS, tinha a função de problematizar questões sociais. Mais recentemente, os ASC têm sido abordados na perspectiva de propiciar a compreensão da natureza da atividade científica e da argumentação (Zeidler et al., 2005). Além desses propósitos, a inclusão de ASC no currículo tem-se dado no sentido de possibilitar uma reflexão crítica de valores (Santos, 2002).

Com essa perspectiva, pode-se afirmar um currículo que tenha a perspectiva de letramento científico implica a ressignificação dos saberes científicos escolares que estão sendo abordados de forma descontextualizada, com uma linguagem hermética, reproduzindo uma falsa imagem de ciência. Enquanto não se caminhar na superação dessa abordagem, a educação científica continuará restringido-se a uma precária alfabetização.

\section{Sistemas de avaliação do nível de alfabetização científica escolar}

Um desafio dos estudos de alfabetização/letramento científico tem sido como medir o grau de alfabetização científica da população escolarizada. Isso vem sendo objeto de preocupação não só no Brasil como em outros países. Foram desenvolvidos projetos visando realizar avaliações comparativas do nível de alfabetização entre diferentes nações, como os estudos do Third International Mathematics and Science Study (TIMSS), o Programme for International Student Assessment (PISA) e o The Relevance of Science 
Education (ROSE). Esses exames têm sido questionados e criticados por seus critérios comparativos; todavia, eles são importantes na medida em que demonstram como a imagem da ciência muda em diferentes culturas e levantam contribuições sobre prioridades a serem levadas em conta na educação científica (Sjøberg, 2002). Apesar de alguns desses exames tentarem incorporar a avaliação da compreensão pública da ciência e não só o conhecimento conceitual, tem havido grande dificuldade na elaboração de questões para medir o grau de entendimento dos estudantes em relação à sua função social. Outro desafio nesse campo tem sido o estabelecimento do que de essencial deve-se avaliar nesses exames. Para Shamos (1995), nesses processos avaliativos é fundamental a definição do papel da educação escolar no sentido do desenvolvimento do interesse dos alunos em questões sociais relativas à ciência.

De maneira, geral, o que se pode afirmar com os resultados desses exames é que a educação científica não vai bem, mesmo em alguns países com elevado grau de escolarização de sua população, tanto no que diz respeito à compreensão dos conceitos básicos como do papel social da ciência. Shamos (1995) aponta vários índices que evidenciam uma crise na alfabetização científica dos Estados Unidos. No Brasil, a situação é das mais críticas. Os estudantes brasileiros tiveram, em 2003, o segundo pior desempenho em ciências entre 41 países pesquisados pelo PISA.

Enquanto se discutem processos avaliativos do nível de educação científica da população, as escolas já consagraram padrões de avaliação segundo critérios bem diversos do que seria a finalidade do letramento científico. No caso do Brasil, de maneira geral, pode-se dizer que as escolas têm avaliado muito mal seus estudantes, com exames que não envolvem aspectos básicos do que se espera do letramento científico.

A escola brasileira continua com caráter elitista, apesar de a Lei de Diretrizes e Bases da Educação Nacional (LDB) preconizar uma educação básica firmada no princípio da igualdade de condições. Na prática, o que se tem é ainda um sistema dual: uma esco- la para a elite e outra para as camadas populares. Enquanto existem escolas, em sua maioria de caráter privado, que têm destino determinado socialmente para a preparação para o acesso aos melhores cursos superiores, existem outras escolas, geralmente públicas, destinadas às classes populares que anseiam exclusivamente pela certificação básica para garantir o acesso ao mercado de trabalho. Em ambos os casos, o parâmetro de referência para os currículos não inclui o que é essencial para o letramento científico.

$\mathrm{O}$ currículo das escolas voltadas à preparação para exames de ingresso em cursos superiores tem-se voltado quase que exclusivamente para os conteúdos e modelos avaliativos adotados pelas instituições de ensino superior às quais elas almejam direcionar seus estudantes. Ocorre que esses exames, apesar do avanço de alguns deles, não avaliam adequadamente muitos dos aspectos essenciais do letramento científico, os quais acabam ficando longe do currículo escolar. O currículo da maioria das outras escolas tem-se limitado às questões bem elementares do processo de alfabetização científica, ou seja, tem-se restringido a conteúdos básicos escolares, geralmente prescritos em livros didáticos que enfatizam a memorização de fórmulas, de sistemas de classificação e da nominalização de fenômenos, bem como a resolução de questões por algoritmos. Esses processos são facilmente avaliados pelos professores e podem ser aprendidos com facilidade pelos alunos, simplificando a tarefa pedagógica e atestando o conhecimento básico em ciência pela posse do seu mais elementar saber: o reconhecimento de alguns de seus vocábulos.

Em síntese, o ensino escolar de ciências, de maneira geral, vem sendo desenvolvido de forma totalmente descontextualizada, por meio da resolução ritualística de exercícios e problemas escolares que não requerem compreensão conceitual mais ampla. Isso corresponde à alfabetização superficial no sentido do domínio estrito vocabular de termos científicos. Esse processo escolar, tanto das escolas preparatórias para o vestibular quanto das que se restringem aos saberes escolares básicos, tem sido conduzido de maneira enfadonha, sem despertar o interesse dos estudantes 
pelo seu estudo, de forma que as disciplinas de ciências têm sido, freqüentemente, odiadas pela maioria dos estudantes.

\section{Considerações finais}

Considerar a alfabetização e o letramento como domínios diferentes da educação científica, mais do que ser uma discussão semântica, evoca processos escolares que busquem formas de contextualização do conhecimento científico em que os alunos o incorporem como um bem cultural que seja mobilizado em sua prática social. Ao adotar uma nova terminologia ainda não conhecida pelos professores, busca-se destacar que se trata de uma concepção de educação científica por meio de uso social.

Assim como se busca em processos de letramento da língua materna o uso social de sua linguagem, reivindicar processos de letramento científico é defender abordagens metodológicas contextualizadas com aspectos sociocientíficos, por meio da prática de leitura de textos científicos que possibilitem a compreensão das relações ciência-tecnologia-sociedade e tomar decisões pessoais e coletivas. Nesse sentido, o conceito de letramento científico amplia a função dessa educação, incorporando a discussão de valores que venham a questionar o modelo de desenvolvimento científico e tecnológico. Em outras palavras, o que se busca não é uma alfabetização em termos de propiciar somente a leitura de informações científicas e tecnológicas, mas a interpretação do seu papel social. Isso implica mudanças não só de conteúdos programáticos como também de processos metodológicos e de avaliação.

Tornar a educação científica uma cultura científica é desenvolver valores estéticos e de sensibilidade, popularizando o conhecimento científico pelo seu uso social como modos elaborados de resolver problemas humanos. Para isso, torna-se relevante o uso de meios informais de divulgação científica, como textos de jornais e revistas e programas televisivos e radiofônicos em sala de aula. Além disso, visitas programadas a espaços não-formais de educação, como museus de ciência, jardins zoológicos, jardins botânicos, planetários, centros de visita de instituições de pesquisa e de parques de proteção ambiental e museus virtuais, entre outros, são importantes estratégias para inculcar valores da ciência na prática social. Não se trata de apresentar um conhecimento esotérico, mas de transformá-lo em conhecimento exotérico, como preconiza Chassot (2000). Nem se trata de imposição cultural, mas sim de reconhecê-la na prática social abrindo as portas da formalização ritualística das fórmulas acadêmicas de sala de aula para seu uso por meios informais. Como já se vem discutindo, a educação científica tem de ser difundida também em espaços não-formais (Krapas \& Rebello, 2001), que podem ser usados não simplesmente para a contemplação, mas também para o entendimento de seu papel social (Marandino, 2006; Leal \& Gouvêa, 2002).

O letramento científico significa também buscar uma educação científica que propicie a educação tecnológica. Muito se tem discutido no meio educacional brasileiro sobre o papel dessa educação, levando em conta argumentos sociológicos. Estando fora do propósito deste artigo uma reflexão ampliada sobre a educação tecnológica, o que se buscou foi apresentar contribuições advindas de estudos de ensino de ciências sobre como essa educação pode ser pensada em disciplinas científicas, por meio de uma abordagem temática contextualizada.

Propiciar, portanto, a educação científica como um processo de domínio cultural dentro da sociedade tecnológica, em que a linguagem científica seja vista como ferramenta cultural na compreensão de nossa cultura moderna, é o grande desafio na renovação do ensino de ciências.

Conforme a concepção que se tenha do papel da educação científica, teremos diferentes concepções de ensino. Se a alfabetização/letramento na educação básica for vista com o papel restrito de ensinar a linguagem científica para realizar exames ou obter certificados, pode-se considerar que o modelo convencional de escolas mais tradicionais atende ao seu propósito, ainda que não propicie aprendizagem sig- 
nificativa nos moldes esperados pelos teóricos de aprendizagem.

Se a função da educação científica na educação básica for a formação de cidadãos letrados em ciência e tecnologia, no sentido que Shamos (1995) considerou "true" scientific literacy (letramento autêntico), será necessário instituir uma ampla reforma no sistema educacional. A situação socioeconômica de nosso país, com mais de 20 milhões de iletrados na própria língua nacional, indica ser esse um objetivo que ainda demandará longo tempo para concretizarse. Na verdade, esse nível elevado de letramento, no sentido do domínio da capacidade de compreensão de modelos científicos, talvez não se venha consolidando nem mesmo em cursos de graduação em ciências, que em geral também mais enfatizam domínio vocabular e resolução de problemas do que compreensão da natureza da atividade científica.

Dentro desses dois extremos de pobreza formativa e mito utópico de letramento ideal, existe um espaço curricular a ser ocupado por meio de ações educativas transformadoras em sala de aula, que está no resgate da função social da educação científica. Para isso, não são necessários laboratórios sofisticados, grade horária ampliada e incorporação de novos conteúdos, mas sim mudanças de propósitos em sala de aula.

Com a caracterização apresentada para o ensino atual de ciências nas escolas, evidenciou-se o que já foi constatado por Barros (1998): a popularização do letramento científico é ainda um mito não atingido e o efeito do currículo formal de ciências parece ser desprezível. Todavia, ao contrapor letramento ao processo elementar de alfabetização, buscou-se demonstrar como esse mito ainda pode ser realizável.

Shamos (1995) também chega a considerar que tornar o público sensível e informado em ciência talvez seja um mito difícil de alcançar. No entanto, refletir sobre concepções de educação científica que estão sendo demandadas pela nossa sociedade pode, de alguma forma, contribuir com aqueles que acreditam que ainda é possível transformar o ensino vocabular ritualístico de preparação para exames em uma educação científica para o domínio da compreensão da ciência como prática social. Afinal, esse é um desafio para curriculistas, avaliadores do sistema educacional, filósofos, sociólogos da educação e, sobretudo, para os professores de ciências que desejam mover-se de uma alfabetização descontextualizada para o letramento científico como prática social.

Certamente não será o modelo de ensino por transmissão do conhecimento como um ornamento cultural para legitimar uma determinada posição social de exclusão da maioria que propiciará a formação de cidadãos conscientes de seu papel na sociedade científica e tecnológica. Nem seriam também livros didáticos - sobrecarregados de conteúdos e socioculturalmente descontextualizados, que apenas ilustram as maravilhas das descobertas científicas, reforçando a concepção de que os valores humanos estão a reboque dos valores de mercado - que iriam contribuir para a formação de cidadãos críticos.

Nesse sentido, mais importante do que a discussão terminológica entre alfabetização e letramento está a construção de uma visão de ensino de ciências associada à formação científico-cultural dos alunos, à formação humana centrada na discussão de valores.

\section{Referências bibliográficas}

AIKENHEAD, Glen S. Science-technology-society. Science education development: from curriculum policy to student learning. In: CONFERÊNCIA INTERNACIONAL SOBRE ENSINO DE CIÊNCIAS PARA O SÉCULO XXI: ACT - Alfabetização em ciência e tecnologia, 1., Brasília, 1990. Anais... Brasília: MEC, 1990 (mimeo.).

What is STS science teaching? In: SOLOMON, Joan; AIKENHEAD, Glen (Eds.). STS Education: international perspectives on reform. New York: Teachers College Press, 1994. p. 47-59. STL and STS: common ground or divergent scenarios? In: JENKINS, Edgar (Ed.). Innovations in science and technology education, vol. VI. Paris: UNESCO Publishing, 1997. p. 77-93.

ALMEIDA JÚNIOR, João Baptista de. A evolução do ensino de Física no Brasil. Revista de Ensino de Física, v. 1, n. 2, p. 45-58, out. 1979. 
ARONS, A. B. Achieving wider scientific literacy. Daedalus: Journal of the American Academy of Arts and Sciences, v. 112, p. 91-122, 1983.

AULER, Décio; DELIZOICOV, Demétrio. Alfabetização científico-tecnológica para quê? Ensaio: pesquisa em educação em ciências, v. 3, n. 1, p. 105-115, 2001.

BAKHTIN, Mikhail. Marxismo e filosofia da linguagem. São Paulo: Hucitec, 1992.

Estética da criação verbal. São Paulo: Martins Fontes, 1997.

BARRA, Eduardo Salles O. A realidade do mundo da ciência: um desafio para a história, a filosofia e a educação científica. Ciência \& Educação, v. 5, n. 1, p. 15-26, 1998.

BARROS, Susana de Souza. Educação formal versus informal: desafios da educação científica. In: ALMEIDA, Maria José P. M. de; SILVA, Henrique César da. (Orgs.). Linguagens, leituras e ensino da ciência. Campinas: Mercado de Letras/Associação de Leitura do Brasil, 1998. p. 69-86.

BAZZO, Walter Antônio. Ciência, tecnologia e sociedade: e o contexto da educação tecnológica. Florianópolis: Ed. da UFSC, 1998. BOURDIEU, Pierre. O campo científico. In: ORTIZ, Renato. Pierre Bourdieu: sociologia. São Paulo: Ática, 1994. p. 122-155 (col. Grandes Cientistas Sociais).

BRASIL. Ministério da Educação (MEC), Secretaria de Educação Média e Tecnológica (SEMTEC). Parâmetros Nacionais para o Ensino Médio. Brasília: MEC/SEMTEC, 1999.

. Ministério da Educação (MEC), Secretaria de Educação Média e Tecnológica (SEMTEC). PCN + Ensino Médio: orientações educacionais complementares aos Parâmetros Curriculares Nacionais - Ciências da Natureza, Matemática e suas Tecnologias. Brasília: MEC/SEMTEC, 2002.

BROWN, Bryan A.; REVELES, John M.; KELLY, Gregory J. Scientific literacy and discursive identity: a theoretical framework for understanding science learning. Science Education, v. 89, n. 5 , p. 779-802, 2005.

CACHAPUZ, António; GIL-PEREZ, Daniel; CARVALHO, Anna Maria Pessoa de; PRAIA, João; VILCHES, Amparo. Superação das visões deformadas da ciência e da tecnologia: um requisito essencial para a renovação da educação científica. In:

(Orgs.). A necessária renovação do ensino das ciências. São Paulo: Cortez, 2005. p. 37-70.

CANIVEZ, Patrice. Educar o cidadão? Campinas: Papirus, 1991. CHAMPAGNE, Audrey B.; LOVITTS, Barbara E. Scientific literacy: a concept in search of definition. In: CHAMPAGNE, Audrey B.; LOVITTS, Barbara E.; CALINGER, Betty J. (Eds.). This year in school science 1989: scientific literacy. Washington: American Association for the Advancement of Science, 1989. p. 1-14.

CHASSOT, Áttico. Alfabetização científica: questões e desafios para a educação. Ijuí: Editora UNIJUÍ, 2000.

Alfabetização científica: uma possibilidade para a inclusão social. Revista Brasileira de Educação, ANPEd, n. 26, p. 89-100, 2003.

DeBOER, George E. Scientific literacy: another look at its historical and contemporary meanings and its relationship to science education reform. Journal of Research in Science Teaching, v. 37, n. 6, p. 582-601, 2000.

DRIVER, Rosalind; ASOKO, H.; LEACH, John; MORTIMER, Eduardo Fleury; SCOTT, Phil. Constructing scientific knowledge in the classroom. Educational Research, v. 23, n. 7, p. 5-12, 1994. FLEMING, Reg. Literacy for a technological age. Science Education, v. 73, n. 4, p. 391-404, 1989.

FOUREZ, Gérard. Science teaching and the STL movement: a socio-historical view. In: JENKINS, Edgar (Ed.). Innovations in science and technology education, v. VI. Paris: UNESCO Publishing, 1997. p. 43-57.

GILBERT, John K. Studies and fields: directions of research in science education. Studies in Science Education, n. 25, p. 173-197, 1995.

GIL-PÉREZ, Daniel. Contribución de la historia y de la filosofía de las ciencias al desarrollo de un modelo de enseñanza/aprendizaje como investigación. Enseñanza de las Ciencias, v. 11, n. 2, p. $197-$ $212,1993$.

GRINSPUN, Mírian Paura Sabrosa Zippin. Educação tecnológica. In: GRINSPUN, Mírian Paura Sabrosa Zippin (Org.). Educação tecnológica: desafios e perspectivas. São Paulo: Cortez, 1999. p. 25-73.

HALLIDAY, M. A. K.; MARTIN, J. R. Writing Science: literacy and discursive power. London: University of Pittsburgh Press, 1993.

HURD, Paul DeHart. Scientific literacy: new minds for a changing world. Science Education, v. 82, n. 3, p. 407-416, 1998.

JENKINS, Edgar. Scientific literacy and school science education. School Science Review, v. 71, n. 256, p. 43-51, 1990.

Scientific and technological literacy: meanings and rationales. In: JENKINS, Edgar (Ed.). Innovations in science and technology education, v. VI. Paris: UNESCO Publishing, 1997. p. 11-39. 
KNORR-CETINA, Karin D. The manufacture of knowledge: an essay on the constructivist and contextual nature of science. Oxford: Pergamon Press, 1981.

KOLSTØ, Stein D. Scientific literacy for citizenship: tools for dealing with the science dimension of controversial socio-scientific issues. Science Education, v. 85, n. 3, p. 291-310, 2001.

KRAPAS, Sonia; REBELLO, Lúcia. O perfil dos museus de ciência da cidade do Rio de Janeiro: a perspectiva dos profissionais. Revista Brasileira de Pesquisa em Educação em Ciências, v. 1, n. 1, p. $68-86,2001$.

KRASILCHIK, Myriam. Inovação no ensino das ciências. In: GARCIA, Walter Esteves (Org.). Inovação educacional no Brasil: problemas e perspectivas. São Paulo: Cortez; Campinas: Autores Associados, 1980, p. 164-180.

. O professor e o currículo das ciências. São Paulo: EDUSP, 1987.

KRASILCHIK, Myriam; MARANDINO, Martha. Ensino de ciências e cidadania. São Paulo: Moderna, 2004.

LATOUR, Bruno; WOOLGAR, Steve. Laboratory fife: the construction of scientific facts. London: Sage, 1979.

LAUGKSCH, Rüdiger C. Scientific literacy: a conceptual overview. Science Education, v. 84, n. 1, p. 71-94, 2000.

LAYTON, David; DAVEY, Angela; JENKINS, Edgar. Science for specific social purposes (SSSP): perspectives on adult scientific literacy. Studies in Science Education, n. 13, p. 27-52, 1986.

LEAL, Maria Cristina; GOUVÊA, Guaracira. Narrativa, mito, ciência e tecnologia: o ensino de ciências na escola e no museu. Ensaio: pesquisa em educação em ciências, v. 2, n. 1, p. 5-36, 2002. LEODORO, Marcos Pires. Pensamento, cultura cientifica e educação. Tese (Doutorado em Educação) - Faculdade de Educação, Universidade de São Paulo, 2005.

LÓPEZ, José L. Luján; CEREZO, José A. López. Educación CTS en acción: enseñanza secundaria y universidad. In: GARCÍA, Marta I. González; CEREZO, José A. López; LÓPEZ, José L. Luján. Ciencia, tecnología y sociedad: una introducción al estudio social de la ciencia y la tecnología. Madrid: Editorial Tecnos, 1996. p. $225-252$.

MACEDO, Beatriz (Org.). Cultura cientifica: um direito de todos. Brasília: UNESCO Brasil, OREALC, MEC, MCT, 2003.

MARANDINO, Martha. Perspectivas da pesquisa educacional em museus de ciências. In: SANTOS, Flávia Maria Teixeira dos; GRECA, Ileana Maria (Orgs.). A pesquisa em ensino de ciências no Brasil e suas metodologias. Ijuí: Editora UNIJUÍ, 2006. p. 89-122.
MATTHEWS, Michael. R. History, philosophy, and science teaching. Science \& Education, v. 1, n. 1, p. 11-47, 1992.

Science teaching: the role of history and philosophy of science. New York: Routledge, 1994.

MEGID NETO, Jorge; FRACALANZA, Hilário; FERNANDES, Rebeca Chiacchio Azevedo. O que sabemos sobre a pesquisa em educação em ciências no Brasil (1972-2004). In: ENCONTRO NACIONAL DE PESQUISA EM EDUCAÇÃO EM CIÊNCIAS, 5., Bauru, 2005. Atas... São Paulo: Abrapec, 2005. 10p. 1 CD-ROM. MERTON, Robert K. Sociologia: teoria e estrutura. São Paulo: Mestre Jou, 1968.

MILLAR, Robin. Towards a science curriculum for public understanding. School Science Review, v. 77, n. 280, p. 7-18, 1996. MILLER, Jon D. Scientific literacy: a conceptual and empirical review. Daedalus: Journal of the American Academy of Arts and Sciences, v. 112, n. 12, p. 29-48, 1983.

MORIN, Edgar. Os sete saberes necessários à educação do futuro. São Paulo: Cortez; Brasília: UNESCO, 2000.

MORTIMER, Eduardo Fleury. Sobre chamas e cristais: a linguagem cotidiana, a linguagem científica e o ensino de ciências. In: CHASSOT, Áttico; OLIVEIRA, Renato José de (Orgs.). Ciência, ética e cultura na educação. São Leopoldo: Ed. UNISINOS, 1998. p. 99-118.

NASCIMENTO, Viviane Briccia do. A natureza do conhecimento científico e o ensino de Ciências. In: CARVALHO, Anna Maria Pessoa de Carvalho (Org.). Ensino de ciências: unindo a pesquisa e a prática. São Paulo: Pioneira Thomson Learning, 2004. p. 35-57. NEWTON, Paul; DRIVER, Rosalind; OSBORNE, Jonathan. The place of argumentation in the pedagogy of school science. International Journal of Science Education, v. 21, n. 5, p. 553576, 1999.

NORRIS, Stephen P.; PHILLIPS, Linda M. How literacy in its fundamental sense is central to scientific literacy. Science Education, v. 87, n. 2, p. 224-240, 2003.

OGBORN, Jon. Advancing physics: contributions of communication and culture to a new physics curriculum (Conferência: Linguagem, cultura e cognição: influências no desenho de um novo currículo de Física). In: ENCONTRO INTERNACIONAL LINGUAGEM, CUlTURA E COGNIÇÃO, 2., Belo Horizonte, 2003. Anais... Campinas: Graf. FE, 2003. 12p. 1 CD-ROM.

OSBORNE, Jonathan; ERDURAN, Sibel; MONK, Martin. Enhancing the quality of argument in school science. School Science Review, v. 82, n. 300, 2001. 
PACEY, Arnold. La cultura de la tecnología. Cidade do México: Fondo de Cultura Económica, 1990.

PEDUZZI, Luiz O. Q. Sobre a utilização didática da história da ciência. In: PIETROCOLA, Maurício (Org.). Ensino de física: conteúdo e epistemologia numa concepção integradora. Florianópolis: Ed. da UFSC, 2001. p. 151-170.

PREWITT, Kenneth. Scientific literacy. Daedalus: Journal of the American Academy of Arts and Sciences, v. 112, n. 2, p. 49-64, 1983.

RADNITZKY, Gerard. Fundamental Schools of Metascience. Göteborg: Akademiforlaget, 1970.

RAMSEY, John. The science education reform movement: implications for social responsibility. Science Education, v. 77, n. 2, p. 235-258, 1993.

RATCLIFFE, Mary. Discussing socio-scientific issues in science lessons: pupils' actions and the teacher's role. School Science Review, v. 79, n. 288, p. 55-59, 1998.

RATCLIFFE, Mary; GRACE, Marcus. Science education for citizenship: teaching socio-scientific issues. Maidenhead: Open University Press, 2003.

ROBERTS, Douglas A. What counts as science education? In: FENSHAM, Peter J. (Ed.). Development and dilemmas in science education. Barcombe: The Falmer Press, 1991. p. 27-55.

ROTH, Wolff.-Michael; LEE, Stuart. Science education as/for participation in the community. Science Education, v. 88, n. 2, p. 263-291, 2004.

RUBBA, Peter. Integration STS into school science and teacher education: beyond awareness. Theory into Practice, v. 30, n. 4, p. 303-315, 1991.

RYDER, Jim. Identifying science understanding for functional scientific literacy: implications for school science education. Studies in Science Education, n. 36, p. 1-44, 2001.

SANTOS, Wildson Luiz Pereira dos. Aspectos sociocientíficos em aulas de química. 2002. Tese (Doutorado em Educação) - Faculdade de Educação, Universidade Federal de Minas Gerais, Belo Horizonte, 2002.

SANTOS, Wildson Luiz Pereira dos; MORTIMER, Eduardo Fleury. Uma análise de pressupostos teóricos da abordagem C-T-S (Ciência-Tecnologia-Sociedade) no contexto da educação brasileira. Ensaio: pesquisa em educação em ciências, v. 2, n. 2, p. 133-162, 2000. SANTOS, Wildson Luiz Pereira dos; SCHNETZLER, Roseli Pacheco. Educação em química: compromisso com a cidadania. Ijuí: Editora da UNIJUÍ, 1997.
SHAMOS, Morris Herbert. The myth of scientific literacy. New Brunswick: Rutgers University Press, 1995.

SHEN, Benjamin S. P. Science literacy. American Scientist, v. 63, n. 3, p. 265-268, 1975.

SJØBERG, Svein. What can we learn from the learners? Some results and implications from "science and scientists" a comparative study in 22 countries. In: INTERNATIONAL ORGANIZATION FOR SCIENCE AND TECHNOLOGY EDUCATION, Symposium, 10., Foz do Iguaçu, 2002. Proceedings... São Paulo: IOSTE, 2002, v. 2. p. 557-568.

SNOW, C. P. As duas culturas e uma segunda leitura: uma versão ampliada das duas culturas e a revolução científica. Trad. de Geraldo Gerson de Souza e Renato de Azevedo Rezende Neto. São Paulo: Editora da Universidade de São Paulo, 1995.

SOARES, Magda. Letramento: um tema em três gêneros. Belo Horizonte: Autêntica, 1998.

SOLOMON, Joan. The dilemma of science, technology and society education. In: FENSHAM, Peter J. (Ed.). Development and dilemmas in science education. London: The Falmer Press, 1988. p. $266-281$.

Teaching science, technology and society. Buckingham: Open University Press, 1993.

STIEFEL, Berta Marco. La naturaleza de la ciencia en los enfoques CTS. Alambique Didáctica de las Ciencias Experimentales, v. 2, n. 3, p. 19-29, 1995.

TEIXEIRA, Paulo Marcelo M. A educação científica sob a perspectiva da pedagogia histórico-social e do movimento CTS no ensino de ciências. Revista Ciência \& Educação, v. 9, n. 2, p. 177190, 2003.

VARGAS, Milton. Para uma filosofia da tecnologia. São Paulo: Editora Alfa-Ômega, 1994.

WAKS, Leonard J. Educación en ciencia, tecnología y sociedad: orígenes, desarrollos internacionales y desafíos actuales. In: MEDINA, Manuel; SANMARTÍN, José(Eds.). Ciencia, tecnología y sociedad: estudios interdisciplinares en la universidad, en la educación y en la gestión política y social. Barcelona: Anthropos; Leioa (Vizcaya): Universidad del País Vasco, 1990. p. 42-75.

WELLINGTON, Jerry; OSBORNE, Jonathan. Language and literacy in science education. Buckingham e Philadelphia: Open University Press, 2001.

YAGER, Robert. Science, technology, society: a major trend in science education. In: UNESCO. New trends in integrated science teaching. Belgian: UNESCO, 1990. p. 44-48. 
YAGER, Robert E.; ROY, R. STS: most pervasive and most radical of reform approaches to "science" education. In: YAGER, Robert E. (Ed.). The science, technology, society movement. Washington: National Science Teachers Association-NSTA, 1993. p. $7-13$.

ZEIDLER, Dana L.; SADLER, Troy D.; SIMMONS, Michael L.; HOWES, Elaine V. Beyond STS: a research-based framework for socioscientific issues education. Science Education, v. 89, n. 3, p. $357-377,2005$.

WILDSON LUIZ PEREIRA DOS SANTOS, doutor em educação pela Universidade Federal de Minas Gerais (UFMG) na área de ensino de ciências, é professor dos Programas de Pós-Graduação em Educação e Pós-Graduação de Ensino de Ciências da Universidade de Brasília (UnB). Desenvolve há mais de dez anos estudos sobre educação científica e cidadania e produção de material didáti- co com essa perspectiva. Principais publicações nessa área de pesquisa: Educação em química: compromisso com a cidadania, em coautoria com Roseli Pacheco Schnetzler (Ijuí: Editora da UNIJUÍ, 1997); Uma análise de pressupostos teóricos da abordagem C-T-S (ciência-tecnologia-sociedade) no contexto da educação brasileira, em co-autoria com Eduardo Fleury Mortimer (Ensaio: pesquisa em educação em ciências, v. 2, n. 2, p. 133-162, 2000); e Química e sociedade, livro didático para o ensino médio, escrito em colaboração com professores do ensino médio, do qual é um dos coordenadores com Gerson de Souza Mól (Nova Geração: São Paulo, 2005). Coordena pesquisa sobre abordagem de aspectos sociocientíficos em aulas de ciências, financiada pelo Conselho Nacional de Desenvolvimento Científico e Tecnológico (CNPq).E-mail: wildson@unb.br

Recebido em fevereiro de 2007 Aprovado em maio de 2007 
Wildson Luiz Pereira dos Santos

Educação científica na perspectiva de letramento como prática social: funções, princípios e desafios

A partir de visões sociológicas e filosóficas sobre ciência, apresenta-se como vêm sendo discutidas historicamente concepções sobre o papel da educação científica. Em seguida, apresenta-se uma revisão da literatura de ensino de ciências sobre significados da educação científica que podem ser entendidos como processos diferenciados de alfabetização e letramento científico. Daí, discute-se como pode ser entendido o processo de letramento científico como prática social, contrapondo-se ao processo elementar de alfabetização científica que vem sendo desenvolvido no ensino atual de ciências. Apresentando contribuições do movimento ciência-tecnologia-sociedade e discutindo aspectos curriculares relativos à natureza e à linguagem científica e aos aspectos sociocientíficos, discutem-se princípios da educação científica voltada para a formação de cidadãos. Ao final, são levantados desafios para o resgate da função social do ensino de ciências, que tem sido visto por alguns como um mito inalcançável.

Palavras-chave: alfabetização científica; letramento científico; ciênciatecnologia-sociedade; ensino de ciências para a cidadania
Scientific education in the perspective of literacy as social practice: functions, principles and

\section{challenges}

Starting from sociological and philosophical visions of science, this article expounds how conceptions on the role of scientific education have been discussed historically. This is followed by a literature review on the teaching of science concerning meanings of scientific education which can be understood as differentiated processes of literacy and scientific literacy. Then it discusses how it is possible to understand the process of scientific literacy as a social practice, in contraposition to the elementary process of scientific literacy which has been developed in current science teaching. After presenting contributions of the sciencetechnology-society movement and discussing curricular questions related to the nature and language of science and to socio-scientific aspects, principles of scientific education directed at the formation of citizenship are raised. Finally, challenges for the recovery of the social function of science teaching which have been seen by some as an unreachable myth, are broached.

Key words: scientific literacy; sciencetechnology-society; science education for citizenship

\section{La educación científica en la} perspectiva del letramiento como práctica social: funciones, principios y desafíos

A partir de visiones sociológicas y filosóficas sobre ciencia, se presenta como vienen siendo discutidas históricamente concepciones sobre el papel de la educación científica. En seguida se presenta una revisión de la literatura de enseñanza de ciencias sobre significados de la educación cientifica que pueden ser entendidos 
como procesos diferentes de alfabetización y letramiento científico. De ahi, se discute como puede ser entendido el proceso de letramiento científico como práctica social, contraponiéndose al proceso elemental de alfabetización cientifica que viene siendo desarrollado en la enseñanza actual de ciencias. Presentando contribuciones del movimiento cienciatecnología-sociedad y discutiendo aspectos curriculares relativos a la naturaleza y al lenguaje científico y a los aspectos sociocientíficos, se discuten principios de la educación cientifica dirigida para la formación de ciudadanos. Al final, son levantados desafios para el rescate de la función social de la enseñanza de ciencias, que ha sido vista por algunos como un mito inalcanzable.

Palabras claves: alfabetización cientifica; letramiento cientifico; ciencia-tecnología-sociedad; enseñanza de ciencias para la ciudadanía 